\title{
A Study to Explore Cultural Child Rearing Practices among Women in Village Manakpura, Patiala
}

\author{
Maninder Kaur ${ }^{1}$, Manpreet Kaur Grewal ${ }^{2}$ \\ ${ }^{1}$ Assistant Professor, Chitkara University, Rajpura \\ ${ }^{2}$ Tutor, Gian Sagar CON, Rajpura
}

\begin{abstract}
Introduction: The child rearing practices differ in communities, depending on their social customs, traditional beliefs and prejudices which may not always be beneficial. Understanding these practices is important for the successful delivery of health messages and services. Aim: The aim of the study was to assess the cultural child rearing practices among women in village Manakpur, Patiala and taking measures (pamphlet distribution) to enhance knowledge of women regarding healthy practices. Material and Methods: This exploratory study was carried out at village Manakpura of dist.Patiala.Total 50 married women having children(0-5)yrs were selected by purposive sampling.After taking written informed consent from them the data was collected using a semistructured interview schedule. Analysis of collected data was done through descriptive statistics. REULTS: $100 \%$ women were following cultural child rearing practices where maximum (44\%) were in the age group of $25-40$ years.89\% of them believed in evil eye and practiced either(24\%) black thread around the neck or (92\%) keeping iron objects under the bed sheet. Although all the subjects believed in giving colostrum to new born, however, $96 \%$ did follow prelacteal feeding practice, only $76 \%$ started breast feed immediately after birth ,56\% continue it till $2 y e a r s$ and only $60 \%$ initiated supplementary feeding at 6 months. $71 \%$ women applied oil, ghee on cord stump for early shedding of cord and to promote healing. 64\%applied kajal in the eyes of child. All the subjects believed in immunization \&toilet training of child . 90\% consulted doctor for child's sufferings like cough, cold, fever and $20 \%$ believe in religious remedies for measles/chickenpox treatments. Conclusion: Different cultures have different child rearing practices, customs and beliefs which affect the upbringing of child. Healthy child rearing practices must be emphasized and faulty practices needs to be corrected by educating the people.
\end{abstract}

Keywords: Childrearing, Breastfeeding, Traditional, Patiala

\section{Introduction \& Background}

Child rearing (CR) refers to bringing-up of children by parents or parent substitutes. It consists of practices that are grounded in cultural patterns and beliefs. Successful child rearing is essential for the child's overall development and realization of self-esteem. As the primary care giver for infant, mother is responsible for attending to all the needs of the infant.The major domains of childrearing during infancy are feeding, meeting the needs of cleaning and protection, including prevention of accidents and injuries, providing appropriate infant stimulation and monitoring growth and development [1]

The traditional practices are time honored rituals and beliefs which are prevalent in a community and they may pertain to a wide range of activities. Every community has its own way of rearing children which is ingrained in the society through traditions established over centuries. The customs and cultural practices pertaining to mother craft and child care are passed on from one generation to another, from grandmother to mother and to their daughters and grand children. The conventional child care practices are based on core knowledge and wisdom although some of them may have emerged purely from intuition, superstitions and unfounded beliefs. The traditional practices are influenced by educational level, socioeconomic status and value system of the family and society [2]

Child rearing practices are a major determinant of morbidity status of infants. Most important of these are the feeding practices. Inadequate and faulty practices of feeding newborns and children also results in under nutrition as reflected by their anthropometric measurements [3].

In the light of information presented above, there is need to explore the Cultural child rearing practices prevalent in community so as to provide information regarding beneficial and harmful practices.

\section{Material and Methods}

A study to explore the cultural child rearing practices was carried out at village Manakpura of district Patiala, Punjab on 50 married women having children $(0-5)$ yrs selected by purposive sampling. A semi-structured interview schedule was prepared for data collection which consisted of 27 questions which were further divided into

Categories: like practices related to cord care, breast feeding, immunization, baby care, weaning, toilet training \& immediately after birth. Written permission from the sarpanch of the village Manakpur and written informed consent was taken from the study sample prior to data collection. Analysis of collected data was done through descriptive statistics.

INGS revealed that $100 \%$ women were following cultural child rearing practices. $83 \%$ women did not allow mother and baby to go outside home after delivery, 53\% did not give bath to baby immediately after birth, $93 \%$ women were following ghurti practices after birth of child, $89 \%$ believed in evil eye, $92 \%$ kept iron objects under the bed sheet of child after birth, 71\% women applied applicant on cord stump, $67 \%$ did not give colostrum to new born and not start 


\section{International Journal of Science and Research (IJSR) \\ ISSN (Online): 2319-7064}

Index Copernicus Value (2015): 78.96 | Impact Factor (2015): 6.391

breast feeding immediately after birth, $87 \%$ gave bottle feed to child. $81 \%$ did not apply anything on BCG scar, $96 \%$ gave massage to baby before bath. $82 \%$ women applied kajal in eyes of baby, $100 \%$ women gave immunization on schedule date, toilet training to child and whistling stimulation to baby during urination. 53\% women started supplementary feeding at the age of 6 month, 79\% women consulted doctor when child suffered from cough, cold, fever and $61 \%$ women did not consult during chicken pox, measles. Aled that $100 \%$ women were following cultural child rearing practices. $83 \%$ women did not allow mother and baby to go outside home after delivery, 53\% did not give bath to baby immediately after birth, $93 \%$ women were following ghurti practices after birth of child, $89 \%$ believed in evil eye, 92\% kept iron objects under the bed sheet of child after birth, 71\% women applied applicant on cord stump, $67 \%$ did not give colostrum to new born and not start breast feeding immediately after birth, $87 \%$ gave bottle feed to child. $81 \%$ did not apply anything on BCG scar, 96\% gave massage to baby before bath. $82 \%$ women applied kajal in eyes of baby, $100 \%$ women gave immunization on schedule date, toilet training to child and whistling stimulation to baby during urination. 53\% women started supplementary feeding at the age of 6 month, 79\% women consulted doctor when child suffered from cough, cold, fever and $61 \%$ women did not consult during chicken pox, measles. Findings revealed that $100 \%$ women were following cultural child rearing practices. $83 \%$ women did not allow mother and baby to go outside home after delivery, $53 \%$ did not give bath to baby immediately after birth, 93\% women were following ghurti practices after birth of child, $89 \%$ believed in evil eye, $92 \%$ kept iron objects under the bed sheet of child after birth, $71 \%$ women applied applicant on cord stump, $67 \%$ did not give colostrum to new born and not start breast feeding immediately after birth, $87 \%$ gave bottle feed to child. $81 \%$ did not apply anything on BCG scar, $96 \%$ gave massage to baby before bath. $82 \%$ women applied kajal in eyes of baby, $100 \%$ women gave immunization on schedule date, toilet training to child and whistling stimulation to baby during urination. 53\% women started supplementary feeding at the age of 6 month, 79\% women consulted doctor when child suffered from cough, cold, fever and $61 \%$ women did not consult during chicken pox, measles. Findings revealed that $100 \%$ women were following cultural child rearing practices. $83 \%$ women did not allow mother and baby to go outside home after delivery, $53 \%$ did not give bath to baby immediately after birth, 93\% women were following ghurti practices after birth of child, $89 \%$ believed in evil eye, $92 \%$ kept iron objects under the bed sheet of child after birth, 71\% women applied applicant on cord stump, $67 \%$ did not give colostrum to new born and not start breast feeding immediately after birth, $87 \%$ gave bottle feed to child. $81 \%$ did not apply anything on BCG scar, $96 \%$ gave massage to baby before bath. $82 \%$ women applied kajal in eyes of baby, $100 \%$ women gave immunization on schedule date, toilet training to child and whistling stimulation to baby during urination. 53\% women started supplementary feeding at the age of 6 month, 79\% women consulted doctor when child suffered from cough, cold, fever and $61 \%$ women did not consult during chicken pox, measles.
Findings revealed that $100 \%$ women were following cultural child rearing practices. $83 \%$ women did not allow mother and baby to go outside home after delivery, 53\% did not give bath to baby immediately after birth, $93 \%$ women were following ghurti practices after birth of child, $89 \%$ believed in evil eye, 92\% kept iron objects under the bed sheet of child after birth, $71 \%$ women applied applicant on cord stump, $67 \%$ did not give colostrum to new born and not start breast feeding immediately after birth, $87 \%$ gave bottle feed to child. $81 \%$ did not apply anything on BCG scar, $96 \%$ gave massage to baby before bath. $82 \%$ women applied kajal in eyes of baby, $100 \%$ women gave immunization on schedule date, toilet training to child and whistling stimulation to baby during urination. 53\% women started supplementary feeding at the age of 6 month, 79\% women consulted doctor when child suffered from cough, cold, fever and $61 \%$ women did not consult during chicken pox, measles.

Findings revealed that $100 \%$ women were following cultural child rearing practices. $83 \%$ women did not allow mother and baby to go outside home after delivery, 53\% did not give bath to baby immediately after birth, $93 \%$ women were following ghurti practices after birth of child, $89 \%$ believed in evil eye, $92 \%$ kept iron objects under the bed sheet of child after birth, 71\% women applied applicant on cord stump, $67 \%$ did not give colostrum to new born and not start breast feeding immediately after birth, $87 \%$ gave bottle feed to child. $81 \%$ did not apply anything on BCG scar, $96 \%$ gave massage to baby before bath. $82 \%$ women applied kajal in eyes of baby, $100 \%$ women gave immunization on schedule date, toilet training to child and whistling stimulation to baby during urination. 53\% women started supplementary feeding at the age of 6 month, 79\% women consulted doctor when child suffered from cough, cold fever and $61 \%$ women did not consult during chicken pox, measles.

\section{Results}

Table 1(a) depicts the distribution of subjects as per their socio- demographic profile. Out of 50 women majority $(44 \%)$ were falling in the age range of ( $25-$ 40 )yrs. $70 \%$ of the subjects belong to joint family and $68 \%$ were sikh by religion where rest $32 \%$ belong to other religions. On the basis of education $26 \%$ were illiterate \& among the educated ones majority ( $42 \%$ ) were educated upto primary level and only $14 \%$ were graduation and above. As per occupation (94\%) were housewives and (6\%) were labourers and none of them were into any kind of jobs or business. $(50 \%)$ of the study subjects had two children and only (14\%) were having 3 or more than 3 children. The sources of information related to childrearing practices were TV/ Radio (44\%) ,newspaper(4\%) and family members $(48 \%)$.

Table 2(a) reveals that all the subjects were following cultural child rearing practices either because of family beliefs (76\%)or to protect the child from evil effect $(24 \%)$.

Table 2(b) revealed that subjects performed religious ceremonies(Path,Mudan) after birth(92\%), hanging materials like neemleaves,lemon,chillies outside the door of mother 


\section{International Journal of Science and Research (IJSR) \\ ISSN (Online): 2319-7064}

Index Copernicus Value (2015): 78.96 | Impact Factor (2015): 6.391

(70\%), giving prelacteal feed to newborn(74\%), wearing black thread around the neck, waist etc (96\%),keeping iron objects (knife,screw,lock) in the vicinity of baby $(80 \%)$ and keeping mother and baby in dark and not allowing them to go out for some days to ward off evil spirits or prevent from evil eye.

Table 2(c) revealed that all the subjects follow the practice of giving colostrum to new born, $76 \%$ beleive in starting breast feed immediately after birth to new born and $56 \%$ continue breastfeed for about 2 years $.78 \%$ believe that because breast feed is not sufficient to satisfy baby's hunger so milk bottles should also be given i.e dont breast feed exclusively and $100 \%$ beleive in supplementary feeding at 6 months of age.

In our study we observed that $76 \%$ mothers applied substances to the umbilical cord, of which $64 \%$ was mustard oil \&others turmeric powder for the early healing \& shedding of the cord.Other important findings of the study revealed that all the subjects believe in getting their baby immunized as per schedule and they do follow (64\%)the practices like applying oil or ghee on the injection sites for better healing.

$90 \%$ subjects believe in giving oil/ghee massage before or after bath to their babies, $64 \%$ beleive in applying kajal in the baby's eyes for either big eye size or to protect from evil eye.Pouring mustard oil in nose/ear often is also believed to be a practise in $56 \%$ subjects to keep the tracts clean.

Among the 50 subjects $68 \%$ beleived in starting toilet training at $1-2$ yrs and rest $32 \%$ at $2-3$ yrs. $76 \%$ train by initially holding the child on their feet and $24 \%$ directly on toilet seat. Where all of them stimulate urination by whistling. $90 \%$ of the subjects always consult the doctor for problems like cough,cold \& fever whereas $10 \%$ go for home remedies. $80 \%$ of the cases believe in consulting doctor for measles and chickenpox whereas $20 \%$ opt other religious remedies like hath aula.

\section{Conclusion}

The findings of this study suggest that some of the childrearing practices followed are similar to the currently recommended practices like giving colostrum, universal practice of breast feeding and immunizing children. Since their perceptions regarding the child rearing practices directly influence the health of the child, certain false beliefs and myths such as applying kajal in eyes and oil/turmeric on cord that are deeply rooted in all strata of community need to be replaced by sound and scientific practices .

\section{Discussion}

Present study aimed at assessing the various child rearing practices and showed that interestingly $100 \%$ gave the colostrum to new born, Similar observations were made in studies conducted abroad as well as in India[4][ 5] but only $76 \%$ started feeding immediately after birth of new born and $96 \%$ were giving prelacteal feeds like honey, sugar etc .In a similar study conducted by [6] it was found that initiation was delayed in the majority of cases $, 24.2 \%, 56.2 \%$ and
$13.6 \%$ mothers began breastfeed on the $2_{\text {nd }}, 3_{\text {rd }}$ and $4_{\text {th }}$ days respectively post-delivery based on traditional beliefs. [7] reported that breast feeding initiation was delayed in almost all cases $>50 \%$ did not initiated for $48 \mathrm{hrs}$ ) prelacteal feed was given and exclusive breast feeding only continued through 2 month.78\% didn't breast feed exclusively(EBF) for 6 months believing that just breast feed does not satisfy baby's hunger so milk bottles should also be given .Studies by [8], [9]reported an EBF rate of $64.4 \%, 68.7 \%$ and $54 \%$. Similar observations were made in a study by [10] where the rate was $70.2 \%$. 90\% subjects believed in giving oil/ghee massage before or after bath to their babiesb where $62 \%$ used johnson baby oil and others used desi ghee /mustard oil/coconut oil. In a similar study by Woldegebriel $\mathbf{A}(\mathbf{2 0 0 2})$ [11] $72.6 \%$ of the mothers in rural area and $56.6 \%$ mothers in urban area practiced massage to their babies. In a similar study [12], $89 \%$ of mothers gave oil massage to their babies.

Application of unhygienic substances on the cord stump is a cause of tetanus neonatorum and infant deaths.In our study we observed that $76 \%$ mothers applied substances to the umbilical cord of which $64 \%$ was mustard oil \& other turmeric powder. This was to make the cord fall faster Similar observations were made in studies [13], where 83\% of the mothers applied turmeric powder on the umbilical stump and by [12] where $58 \%$ of mothers applied substances on the umbilical cord.

Applying Kajal to the eye or face is age old traditional belief considered to ward off evil, with the added cosmetic benefit of making the baby's eye look bigger and more beautiful. However, its application to the eye can cause conjunctivitis and dacrocystitis, and finger nail trauma to the eye can also occur [14] $64 \%$ of the mothers in our study applied kajal to the baby's eye, among whom $20 \%$ did so to ward off evil, $4 \%$ applied it as a part of tradition and $76 \%$ to make the baby look beautiful

Present study revealed that subjects performed religious ceremonies (Path, Mudan) after birth(92\%),hanged materials like neem leaves, lemon, chillies outside the door of mother $(70 \%)$, wore black thread around the neck, waist (96\%),kept iron objects (knife, screw, lock) in the vicinity of baby $(80 \%)$ and kept mother and baby in dark and not allowed them to go out for some days to ward off evil spirits or prevent from evil eye. Study conducted by [6] revealed similar findings like they believed in keeping mothers in dark for a month after delivery, splanishing the water over head of baby, to keep the iron element, neem leaves, hanging mango leaves at the doorstep after birth of the baby. In this $100 \%$ subjects used whistling stimulation for toilet training of children .Similar findings were observed on $57.5 \%$ subjects in a study by [6].

\section{Limitations \& Scope}

This study is limited to single setting \& limited sample. Similar studies should be conducted in other parts of the country which will give an insight into the prevalent infant rearing and feeding practices and we can understand cultural influences on breast feeding and child rearing practices in depth among the general population

\section{Volume 6 Issue 1, January 2017




\section{International Journal of Science and Research (IJSR) \\ ISSN (Online): 2319-7064 \\ Index Copernicus Value (2015): 78.96 | Impact Factor (2015): 6.391}

Table 1(a): Distribution of subjects as per their sociodemographic profile.

\begin{tabular}{|c|c|c|}
\hline Socio-demographic variables & $n$ & $f(\%)$ \\
\hline $\begin{array}{c}\text { Age (in years) } \\
<25 \\
25-40 \\
41-60 \\
>60\end{array}$ & $\begin{array}{l}10 \\
22 \\
09 \\
09\end{array}$ & $\begin{array}{l}20 \% \\
44 \% \\
18 \% \\
18 \%\end{array}$ \\
\hline $\begin{array}{c}\text { Family } \\
\text { Nuclear } \\
\text { Joint }\end{array}$ & $\begin{array}{l}15 \\
35\end{array}$ & $\begin{array}{l}30 \% \\
70 \%\end{array}$ \\
\hline $\begin{array}{l}\text { Religion } \\
\text { Sikh } \\
\text { Hindu } \\
\text { Christian } \\
\text { Muslim } \\
\end{array}$ & $\begin{array}{l}34 \\
14 \\
00 \\
02 \\
\end{array}$ & $\begin{array}{l}68 \% \\
28 \% \\
00 \% \\
04 \% \\
\end{array}$ \\
\hline $\begin{array}{l}\text { Education } \\
\text { Illiterate } \\
\text { Primary } \\
\text { Secondary } \\
\text { Graduation \& above }\end{array}$ & $\begin{array}{l}13 \\
21 \\
09 \\
07\end{array}$ & $\begin{array}{l}26 \% \\
42 \% \\
18 \% \\
14 \%\end{array}$ \\
\hline $\begin{array}{l}\text { Occupation } \\
\text { Housewife } \\
\text { Business } \\
\text { Govt/private } \\
\text { Labour }\end{array}$ & $\begin{array}{l}47 \\
00 \\
00 \\
03\end{array}$ & $\begin{array}{l}94 \% \\
00 \% \\
00 \% \\
06 \%\end{array}$ \\
\hline $\begin{array}{c}\text { Number of children } \\
\text { One } \\
\text { Two } \\
\text { Three } \\
\text { More } \\
\end{array}$ & $\begin{array}{l}11 \\
25 \\
07 \\
07 \\
\end{array}$ & $\begin{array}{l}22 \% \\
50 \% \\
14 \% \\
14 \% \\
\end{array}$ \\
\hline $\begin{array}{l}\text { Source of information } \\
\text { Newspaper } \\
\text { T.V./Radio } \\
\text { Internet } \\
\text { Family member } \\
\end{array}$ & $\begin{array}{l}02 \\
22 \\
02 \\
24 \\
\end{array}$ & $\begin{array}{l}04 \% \\
44 \% \\
04 \% \\
48 \%\end{array}$ \\
\hline
\end{tabular}

Table 1(b): Frequency and Percentage distribution of subjects related to cultural child rearing practices.

\section{$\mathrm{N}=50$}

\begin{tabular}{|l|c|c|}
\hline \multicolumn{1}{|c|}{ Child Rearing Practices } & $F$ & $(\%)$ \\
\hline 1A.Do you follow cultural child rearing & & \\
practices? & 50 & $100 \%$ \\
a) Yes & 00 & $00 \%$ \\
b) No & & \\
& 38 & $76 \%$ \\
1B. If yes, why? & 12 & $24 \%$ \\
a) Because of family belief. & \\
b) To protect the baby from evil \\
effects.
\end{tabular}

Table 2(b): Agreement of respondents regarding various cultural child rearing practices immediately after birth:-

\begin{tabular}{|l|l|l|}
\hline \multicolumn{1}{|c|}{ Practices Immediately after birth } & $\mathrm{f}$ & $\%$ \\
\hline $\begin{array}{l}\text { 1.Performing religious Ceremony (Path,Mundan) } \\
\text { after the birth of baby to eradicate the evil spirits/ } \\
\text { tradition beliefs }\end{array}$ & 46 & 92 \\
\hline $\begin{array}{l}\text { 2.Hanging material like neemleaves,lemon,green } \\
\text { chillies outside the door of mother's room }\end{array}$ & 35 & 70 \\
\hline $\begin{array}{l}\text { 3.Not allowing mother and newborn to go out for } \\
\text { some days and to keep them in dark to prevent from } \\
\text { evil eye . }\end{array}$ & 37 & 74 \\
\hline 4.Giving prelacteal feed(ghurti)like honey,sugar. & 48 & 96 \\
\hline $\begin{array}{l}\text { 5.Wearing black thread around the neck or tyeing } \\
\text { wheat around the wrist of baby to prevent from evil } \\
\text { eye }\end{array}$ & 37 & 74 \\
\hline $\begin{array}{l}\text { 6.Keeping iron objects in the vicinity of baby like } \\
\text { knife,lock,screw }\end{array}$ & 40 & 80 \\
\hline
\end{tabular}

Table 2(c): Agreement of respondents regarding various cultural child rearing practices related to breast feeding \& weaning:-

\begin{tabular}{|l|c|l|}
\hline \multicolumn{1}{|c|}{ Practices related to breast feeding \& Weaning } & f & $\%$ \\
\hline 1. Giving the first milk (colostrum) to new born? & 50 & 100 \\
\hline $\begin{array}{l}\text { 2. Starting breast feeding immediately after birth of } \\
\text { new born }\end{array}$ & 38 & 76 \\
\hline 3. Continuing breastfeeding for 2 yrs of age of baby & 28 & 56 \\
\hline $\begin{array}{l}\text { 4. Using milk bottles as a complementary feeding } \\
\text { method }\end{array}$ & 39 & 78 \\
\hline $\begin{array}{l}\text { 5. Starting supplementary feeding at 6 months or } \\
\text { beyond }\end{array}$ & 50 & 100 \\
\hline
\end{tabular}

\section{References}

[1] Saramma P.P, Thomas Sanjeev V. Child rearing knowledge and practice scales for women with epilepsy at Kerala State, India: Annuals of Indian Academy of Neurology July-September 2010; 13 (3): 171.

[2] Singh M. Care of new born. $1^{\text {st }}$ ed. New Delhi: Jaypee Brothers, 2001.132-33.

[3] Joseph N. A longitudinal study on infant rearing practices: Journal of family medicine and primary care 2013; $2: 37-43$

[4] Kulkarni RN, Anjenaya S, Gujar R. Breast Feeding Practices in an Urban Community of Kalamboli, Navi Mumbai. Indian J Community Med. 2004; 29(4):17980.

[5] Ali S, Ali SF, Imam AM, Ayub S, Billoo AG. Perception and practices of breastfeeding of infants 0-6 months in an urban and a semi-urban community in Pakistan: a cross-sectional study. J Pak Med Assoc. 2011; 61(1):99-104.

[6] Thakur K. Kaur D. Jaspal S. Puri N. To assess cultural beliefs, customs and norms in child rearing practices at rural community of district Patiala: Baba Farid University Nursing Journal. June 2013; 4(1): 68-72.

[7] Patrice L E.Infant feeding styles:Barriers and opportunities for good nutrition in India.Nutrition reviews .May 2002;60(5):S109-14.

[8] Qiu L, Zhao Y, Binns CW, Lee AH, Xie X. A cohort study of infant feeding practices in city, suburban and rural areas in Zhejiang Province, PR China. Int Breastfeed J.2008, 3:4-6.

[9] Parveen N, Majeed R, Khawaja MA. Evaluation of breast feeding practices. Gomal J Med Sci.2009; $7(1): 14-6$

[10] Madhu K, Chowdary S, Masthi R. Breast feeding practices and newborn care in rural areas: a descriptive cross-sectional study. Indian J Community Med. 2009; 34(3):243-6.

[11] Woldegebriel A. Mothers' knowledge and belief on breast feeding. Ethiop Med J. 2002;40(4):365-74.

[12] Alam MA, Ali NA, Sultana N et al. Newborn umbilical cord and skin care in Sylhet District,Bangladesh: implications for the promotion of umbilical cord cleansing with topicalchlorhexidine. J Perinatol.2008; 28(2):61-8.

[13] Ayaz A, Saleem S. Neonatal Mortality and Prevalence of Practices for Newborn Care in a Squatter Settlement of Karachi, Pakistan: A Cross-Sectional Study. Plos One. $2010 ; 5(11)$ 


\section{International Journal of Science and Research (IJSR) \\ ISSN (Online): 2319-7064}

Index Copernicus Value (2015): 78.96 | Impact Factor (2015): 6.391

[14] Vaishnav R. An example of the toxic potential of traditional eye cosmetics. Indian J Pharmacol.2001; 33:

$46-48$

\section{Author Profile}

Maninder Jeet Kaur is Assistant Professor (OBG),

Chitkara School of Health Sciences, Chitkara

University, Rajpura,Punjab

Manpreet Kaur Grewal is Nursing Tutor (Child

Health Nursing) Gian Sagar College of Nursing, Rajpura, Patiala. 